\title{
Communication
}

\section{A Fluorescent Sensor for Dinitrobenzoic Acid Based on a Cyanuric Acid and Xanthene Skeleton}

\author{
Francisco M. Muñiz ${ }^{1}$, Luis Simón ${ }^{1}$, Silvia Sáez ${ }^{1}$, César Raposo ${ }^{2}$, Victoria Alcázar ${ }^{3}$ and \\ Joaquín R. Morán ${ }^{1}$ * \\ ${ }^{1}$ Organic Chemistry Department, Plaza de los Caídos, 1-5, University of Salamanca, 37008 \\ Salamanca, Spain \\ ${ }^{2}$ Mass Spectrometry Service, Plaza de los Caídos, 1-5, University of Salamanca, 37008 Salamanca, \\ Spain \\ 3 Industrial Chemical Engineering, Calle José Gutiérrez Abascal, 2, Madrid Polytechnical University, \\ 28006 Madrid, Spain
}

* Author to whom correspondence should be addressed; E-mail: romoran@usal.es

Received: 12 February 2008 / Accepted: 11 March 2008 / Published: 11 March 2008

\begin{abstract}
A new fluorescent sensor based on a dimethylxanthene skeleton has been synthesized. Because of its oxyanion hole structure, this receptor includes a suitable cavity for the association of carboxylic acids. The receptor's fluorescence is quenched upon addition of dinitrobenzoic acid.
\end{abstract}

Keywords: Dimethylxanthene, fluorescent sensor, molecular recognition, carboxylic acid receptor, oxyanion hole.

\section{Introduction}

In the development of new organic receptors, enzymes are a unique source of inspiration. Many enzymes characteristically feature oxyanion holes, in which a carbonyl group can be placed, setting two strong linear hydrogen bonds. Oxyanion holes can be mimicked using simple organic molecules such as isophthalic acid [1], biphenylene [2], 2,6-pyridinedicarboxylic acid [3], xylylenediamine [4,5], chromenones [6], acridones [7,8], xanthones [9,10] and xanthenes [11] (Figure 1). 
Figure 1. Oxyanion hole of the enoyl-CoA hydratase with a superimposed 4,5diacetamidoxanthene, showing the similarity of the H-bonds (level of theory: HF/6-31G).
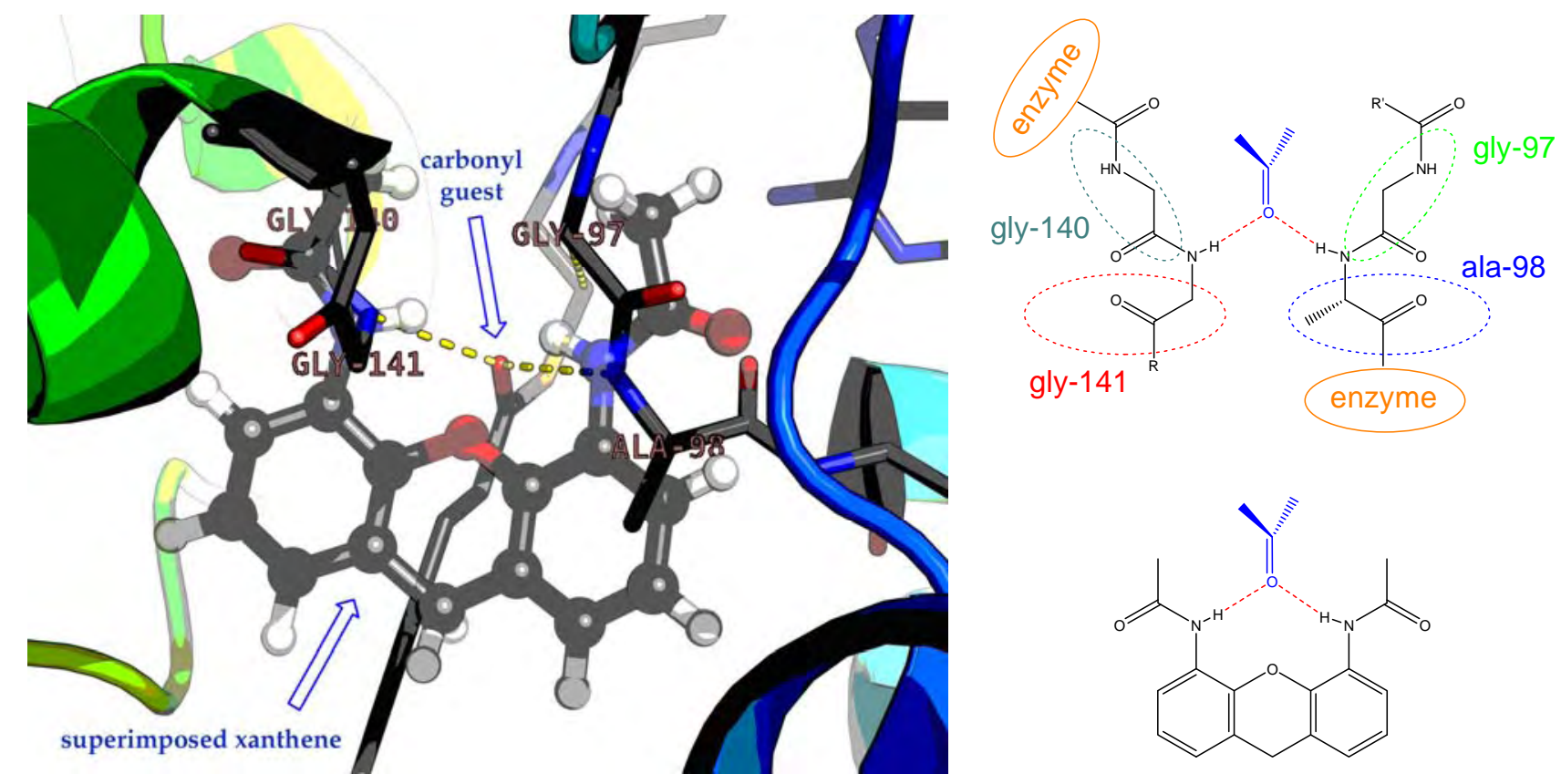

\section{Results and Discussion}

For the present work, we chose xanthenes since they offer reasonable rigidity and do not show a strong tendency to self association as xanthones. 9,9-Dimethylxanthene can be obtained from the commercially available xanthone and trimethyl aluminum [12]. Bulky tert-butyl groups have been used to block the C-2 and C-7 positions from electrophilic substitution [13], but nitration yields a large degree of ipso substitution [14]. Accordingly, chlorine atoms have been used for this purpose. Nitration followed by reduction, as shown in figure 2, yielded the 2,7-dichloro-9,9-dimethylxanthene4,5-diamine. This amine can be selectively acylated at one of the nitrogen atoms due to an aggregation effect [15].

Scheme 1. Preparation of the $N$-Boc-protected xanthenediamine.<smiles>CC(C)C(C)C(C)C</smiles><smiles>CC(C)C(C)(C)C(=O)Nc1cc(Cl)cc2c1Oc1c(N)cc(Cl)cc1C2(C)C</smiles>

i) $\mathrm{Me}_{3} \mathrm{Al}$, tol, $0^{\circ} \mathrm{C}, 14 \mathrm{~h}$ ii) $\mathrm{SO}_{2} \mathrm{Cl}_{2}, \mathrm{CCl}_{4}, \mathrm{rt}, 24 \mathrm{~h}$ iii) $\mathrm{HNO}_{3}$ (fum), $\mathrm{CH}_{2} \mathrm{Cl}_{2}, \mathrm{rt}, 14 \mathrm{~h}$

iv) $\mathrm{SnCl}_{2} \times 2 \mathrm{H}_{2} \mathrm{O}, \mathrm{EtOH}$, reflux, $1 \mathrm{~h}$ v) $\mathrm{Boc}_{2} \mathrm{O}, \mathrm{CHCl}_{3}, \mathrm{AcOH}(0,05 \mathrm{eq}), 7$ days 
A straightforward application of this xanthene is the preparation of a carboxylic acid sensor. Thus, a cyanuric acid fragment was included in one of the amino groups while in the other a highly fluorescent dansyl group was inserted. Scheme 2 shows the preparation of this compound (see experimental details in the supplementary material), henceforth referred to as daxacyan because its fragments are a dansyl

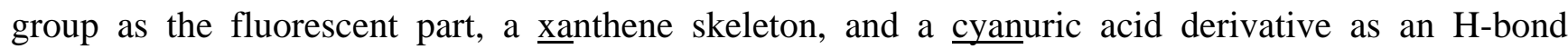
acceptor.

Figure 3. Synthesis of daxacyan.<smiles>CC(C)(C)Nc1cc(Cl)cc2c1Oc1c(N)cc(Cl)cc1C2(C)C</smiles><smiles></smiles><smiles>CC(C)(C)Nc1cc(Cl)cc2c1Oc1c(Nc3nc(Cl)nc(Cl)n3)cc(Cl)cc1C2(C)C</smiles>

1<smiles>CCOc1nc(Nc2cc(Cl)cc3c2Oc2c(NS(=O)(=O)c4cccc5c(N(C)C)cccc45)cc(Cl)cc2C3(C)CC(C)(C)C)nc(OCC)n1</smiles><smiles>[Y]C#CC</smiles>

i) 2,4,6-trichloro-1,3,5-triazine (1,2 eq), $\mathrm{CH}_{2} \mathrm{Cl}_{2}$, rt, 5 min ii) $\mathrm{H}_{2} \mathrm{O}$, rt, $14 \mathrm{~h}$ ii) $\mathrm{H}_{2} \mathrm{SO}_{4}$, THF, EtOH, rt, $14 \mathrm{~h}$ iii) dansyl chloride (1,1 eq), pyr, rt, 30 min

The ${ }^{1} \mathrm{H}-\mathrm{NMR}$ spectrum of daxacyan shows that the aromatic proton ortho to the aminocyanuric acid (H-6) at the expected position at $8.11 \mathrm{ppm}$, while the proton ortho to the dansyl group (H-3) absorbs at a higher field at $7.26 \mathrm{ppm}$. Owing to this large difference in chemical shifts, we propose the conformation shown in figure 4 for daxacyan, in which H-3 stands in the naphthyl group shielding cone.

Figure 2. Conformation of the dansyl group for daxacyan, where the interaction between $\mathrm{H}-3$ and the dansyl group can be observed.<smiles>CCOc1nc(Nc2c(C)c(Cl)cc3c2Oc2c(NS(=O)(=O)c4cccc5c(N(C)C)cccc45)cc(Cl)cc2C3(C)C)nc(OCC)n1</smiles>

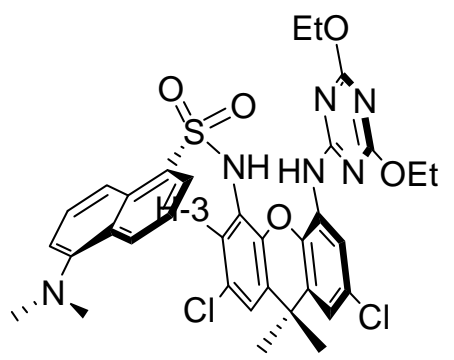


Another interesting point is that in a solution of chloroform the chemical shifts of the daxacyan protons change with the concentration. From the data obtained here it is possible to deduce that in chloroform daxacyan forms a dimer with a $\mathrm{K}_{\mathrm{dim}}=4.5 \mathrm{M}^{-1}$ (see supplementary material). Since the largest chemical shift movements in the dimer are observed for $\mathrm{NH}$ protons, which move from 7.56 ppm and $7.71 \mathrm{ppm}$ to $8.21 \mathrm{ppm}$ and $9.96 \mathrm{ppm}$ respectively, H-bonds are probably responsible for the stabilization of the dimer. Figure 3 shows this proposed structure.

Figure 3. Proposed dimeric structure for daxacyan.

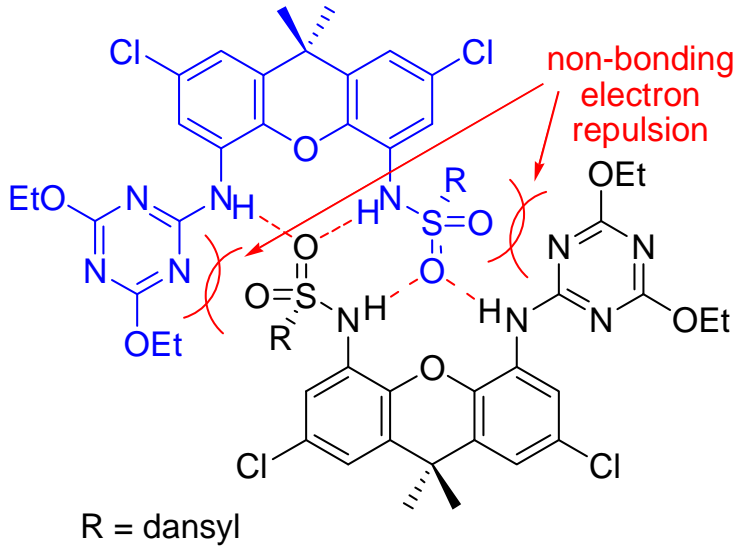

The chemical shifts in the dimer are in agreement with the proposed structure. The xanthene aromatic protons show very small movements, while the dansyl protons (H-3' and H-7') are shielded by almost $0.3 \mathrm{ppm}$ due to the presence of the xanthene anisotropic cone or to the other dansyl group. The cyanuric acid ethyl groups show the largest shifts from $4.53 \mathrm{ppm}$ to $4.18 \mathrm{ppm}(\Delta \delta=0.35 \mathrm{ppm})$ in the dimer due to the influence of the xanthene ring.

Amides and imides form complexes with daxacyan. Since imides have more acidic protons, we expected these compounds to form stronger associates with the daxacyan than the amides. Surprisingly, the opposite result was obtained. From a competitive study it was observed that the valerolactam forms a complex 4.1 times stronger than the glutarimide (see supplementary material). The repulsion of the non-bonding electrons of the oxygens of the cyanuric ethyl groups and the imide carbonyl, are probably responsible for this effect, as seen in Figure 4.

Figure 4. Weak complex between daxacyan and glutarimide and its non-bonding electron repulsion.<smiles></smiles> 
Due to their acidic proton, carboxylic acids are better guests than amides. Adding small amounts of acetic, benzoic or decanoic acids to the solution of daxacyan in chloroform induces in their ${ }^{1} \mathrm{H}-\mathrm{NMR}$ spectra large shifts in the signals of the NH protons, which move from $7.26 \mathrm{ppm}$ and $7.75 \mathrm{ppm}$ to absorptions beyond $9 \mathrm{ppm}$. To quantitatively estimate the stability of these complexes, decanoic acid was chosen. Plotting the shifts of $\mathrm{H}-6$ proton of the receptor during titration with decanoic acid provides an association constant of $\mathrm{K}_{\mathrm{ass}}=1.4 \times 10^{3} \mathrm{M}^{-1}$ (see supplementary material). The geometry proposed for this complex and the chemical shifts obtained for the associate are shown in Figure 5.

Figure 5. Proposed geometry for the associate between daxacyan and decanoic acid and the chemical shifts of its protons.
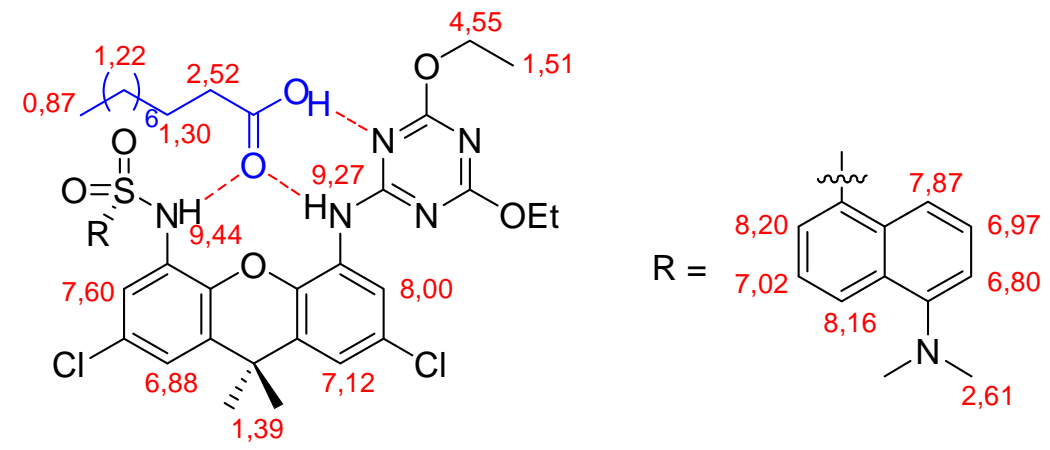

Since daxacyan has a fluorescent dansyl group, it could act as a sensor. Accordingly, the changes in light emission were tested in the presence of several carboxylic acids in chloroform. Essentially, decanoic and benzoic acids did not change the receptor fluorescence; phthaloylalanine, dinitrobenzoylglycine and dinitrobenzoylleucine only elicited small decreases in it, and only dinitrobenzoic acid induced a large quenching, as shown in Figure 6. Detection of 3,5-dinitrobenzoic acid is interesting because this compound is a by-product of many industrial processes, like the manufacture of pesticides, dyes or explosives [16].

Figure 6. Changes in the fluorescence of the daxacyan receptor.

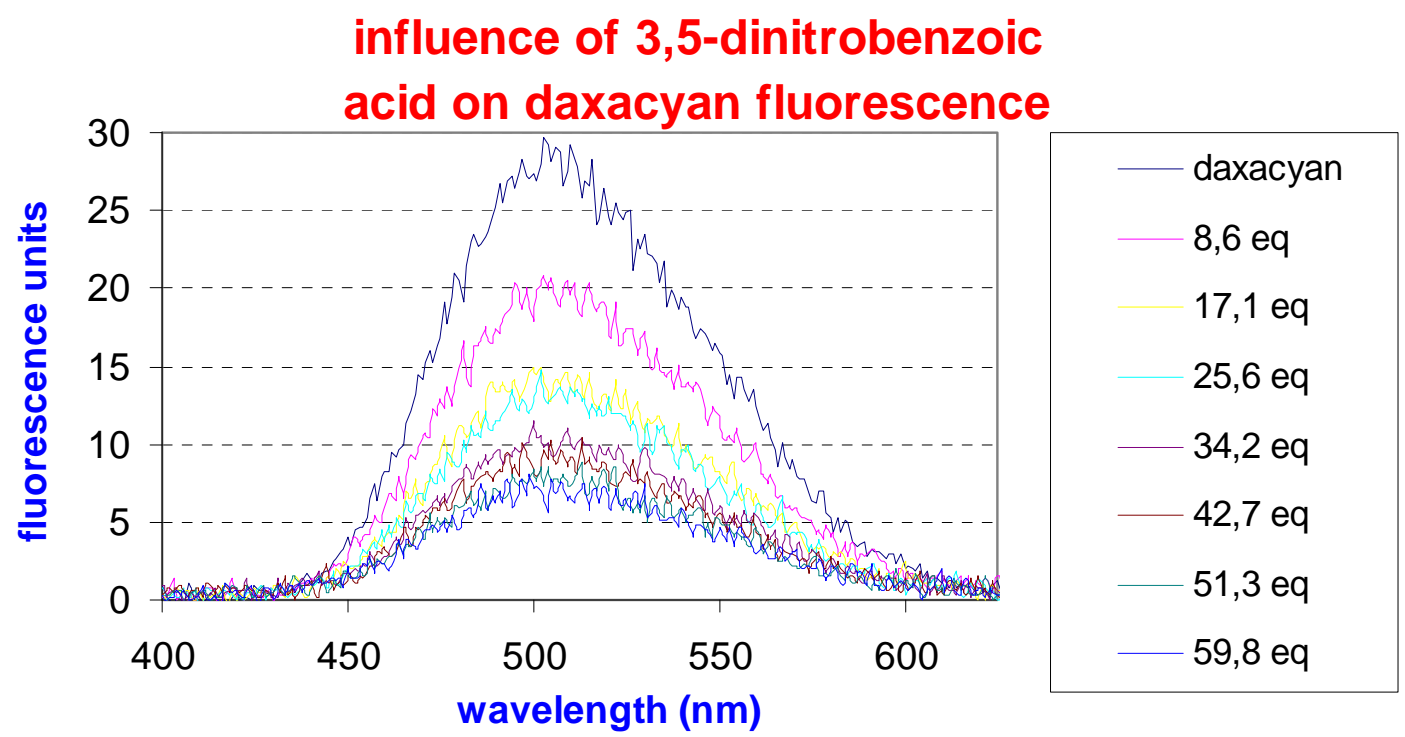


From the quenching of the fluorescence in the presence of dinitrobenzoic acid, an association constant of $\mathrm{K}_{\mathrm{ass}}=8.5 \times 10^{3} \mathrm{M}^{-1}$ can be deduced (see supplementary material). In our opinion, a PET effect $[17,18]$ could be responsible for the loss of fluorescence of daxacyan in the presence of dinitrobenzoic acid, since this guest is a good oxidant and may trap the excited electron of the dansyl.

To check that the lack of activity of the other guests did not correspond to a lack of association, the $\mathrm{K}_{\text {ass }}$ were measured making use of NMR titrations in $\mathrm{CDCl}_{3}$. Phthaloylalanine afforded the same association constant as decanoic acid, $\mathrm{K}_{\mathrm{ass}}=1.4 \times 10^{3} \mathrm{M}^{-1}$, which is surprising taking into account the different steric demands of both guests (see supplementary material). Stacking interactions between the phthaloyl group and the xanthene aromatic ring may explain the similar association constants. Further evidence for this effect can be seen in the chemical shifts found for the complexes of both acids. While in the decanoic acid complex H-3 in the xanthene is deshielded by $\Delta \delta=-0.30 \mathrm{ppm}$, in the phthaloyl associate this same proton is shielded by $\Delta \delta=+0.20 \mathrm{ppm}$; i.e., a total difference of $0.5 \mathrm{ppm}$. Figure 7 shows that H-3 may stand in the phthaloyl shielding cone in the complex.

Figure 7. Proposed structure for the complex between daxacyan and the phthaloylalanine.
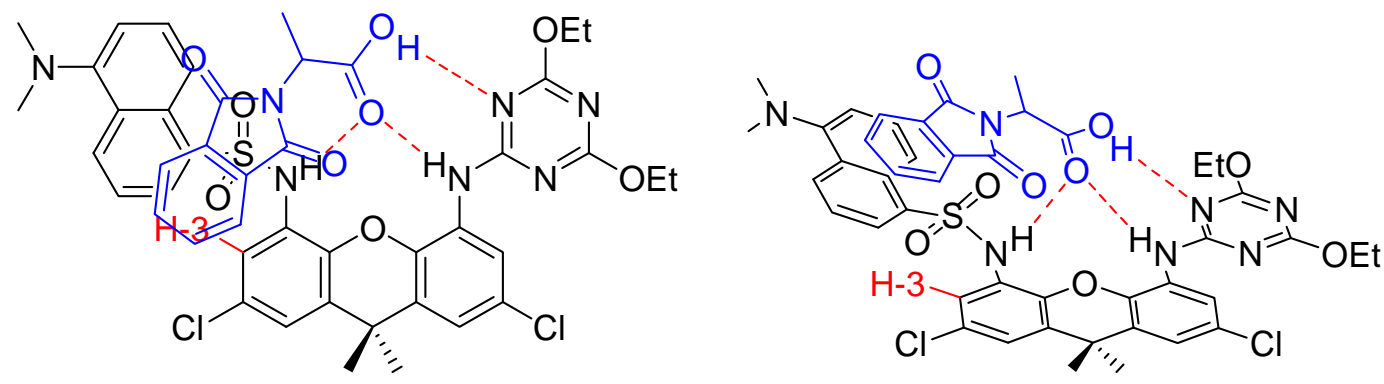

Even larger shieldings of $\mathrm{H}-3$ are generated in the complexes of dinitrobenzoylglycine and dinitrobenzoylleucine, close to $\Delta \delta=+0.3 \mathrm{ppm}$ in both cases. Since the latter guest shows better solubility in chloroform it was chosen to assess its association constant. From a competitive experiment with phthaloylalanine an association constant was established, $\mathrm{K}_{\mathrm{ass}}=1.4 \times 10^{4} \mathrm{M}^{-1}$, for the dinitrobenzoylleucine; higher than with dinitrobenzoic acid (see supplementary material). Probably a stacking or charge transfer effect between the dinitrobenzoyl group and the xanthene are responsible for the high association constant of the dinitrobenzoyl amino acids, while this same effect fixed the geometry in the complex such that the dinitrobenzoyl and the dansyl groups stand apart from each other and no effective electron transfer is possible.

In conclusion, daxacyan is a good receptor for carboxylic acids but it only acts as a sensor for dinitrobenzoic acid.

\section{Supplementary Material}

Synthetic methods and characterization data for compounds 1, 2 and daxacyan receptor. NMR spectra for the decanoic acid-daxacyan complex. Dimerization titration. Competitive titrations with several guests related in the manuscript. NMR titration of decanoic acid. Fluorescent titration of 3,5dinitrobenzoic acid. 


\section{Acknowledgements}

The authors thank the Spanish Dirección General de Investigación, Ciencia y Tecnología (DGICYT) (CTQ-2005-074007bqu) and the Junta de Castilla y León (JCL) (SA 52/03) for their support in this work. The Spanish Ministerio de Educación y Ciencia (MEC) is acknowledged for the fellowships (F. M. M., L. S. and S. S.). They also thank Emilio Calle for the fluorescent spectra.

\section{References}

1. Curran, D. P.; Kuo, L. H. Acceleration of a dipolar Claisen rearrangement by hydrogen bonding to a soluble diaryl urea. Tetrahedron Lett. 1995, 36, 6647-6650.

2. Kelly, T. R.; Meghani, P.; Ekkundi, V. S. Diels-Alder reactions: Rate acceleration promoted by a biphenylenediol. Tetrahedron Lett. 1990, 31, 3381-3384.

3. Hunter, C. A. Molecular recognition of p-benzoquinone by a macrocyclic host. J. Chem. Soc. Chem. Commun. 1991, 749-751.

4. Nishizawa, S.; Bühlmann, P.; Iwao, M.; Umezawa, Y. Anion recognition by urea and thiourea groups remarkably simple neutral receptor for dihydrogenphosphate. Tetrahedron Lett. 1995, 36, 6483-6486.

5. Jubian, V.; Veronese, A.; Dixon, R. P.; Hamilton, A. D. Acceleration of a phosphate diester transesterification reaction by bis(alkylguanidinium) receptors containing an appended general base. Angew. Chem. Int. Ed. Eng. 1995, 34, 1237-1239.

6. Raposo, C.; Almaraz, M.; Crego, M.; Mussons, M. L.; Pérez, N.; Caballero, M. C. Morán, J. R. Lactone receptors with catalytic activity. Tetrahedron Lett. 1994, 35, 7065-7068.

7. García-Garrido, S. E.; Caltagirone, C.; Light, M. E.; Gale, P. A. Acridinone-based anion receptors and sensors. Chem. Commun. 2007, 1450-1452.

8. Blázquez, M. T.; Muñiz, F. M.; Sáez, S.; Simón, L. M.; Alonso, A.; Raposo, C.; Lithgow, A.; Alcázar, V.; Morán, J. R. Acridone heterocycles as fluorescent sensors for anions. Heterocycles 2006, 69, 73-81.

9. Crego, M.; Raposo, C.; Mussons, M. L.; Berrocal, A.; Caballero, M. C.; Morán, J. R. Active receptors in the nucleophilic addition of pyrrolidine to acrylamide. Heterocycles 1995, 40, 139140.

10. Simón, L.; Muñiz, F. M.; Sáez, S.; Raposo, C.; Morán, J. R. From theozymes to artificial enzymes: Enzyme-like receptors for Michael additions with oxyanion holes and active amino groups. Eur. J. Org. Chem. 2007, 4821-4830.

11. Shimizu, K. D.; Dewey, T. M.; Rebek, J. Jr. Convergent functional groups. 15. Synthetic and structural studies of large and rigid molecular clefts. J. Am. Chem. Soc. 1994, 116, 5145-5149.

12. Nowick, J. S.; Ballester, P.; Ebmeyer, F.; Rebek, J. Jr. Convergent functional groups. 9. Complexation in new molecular clefts. J. Am. Chem. Soc. 1990, 112, 8902-8906.

13. Hamann, B. C.; Branda, N. R.; Rebek, J. Jr. Multipoint recognition of carboxylates by neutral hosts in non-polar solvents. Tetrahedron Lett. 1993, 34, 6837-6840.

14. Chang, K. J.; An, Y. J.; Uh, H.; Jeong, K. S. Reversible control of assembly and disassembly of interlocked supermolecules. J. Org. Chem. 2004, 69, 6556-6563. 
15. Muñiz, F. M.; Simón, L.; Sáez, S.; Raposo, C.; Morán, J. R. Selective acylation of 4,5-diamino9,9'-dimethylxanthene through an aggregation effect. Tetrahedron Lett. 2008, 49, 790-793.

16. Hallas, L. E.; Alexander, M. Microbial transformation of nitroaromatic compounds in sewage effluent. Appl. Environ. Microbiol. 1983, 1234-1241.

17. De Santis, G.; Fabbrizzi, L.; Licchelli, M.; Poggi, A.; Taglietti, A. Molecular recognition of carboxylate ions based on the metal-ligand interaction and signalled through fluorescence quenching. Angew. Chem. Int. Ed. Eng. 1996, 35, 202-204.

18. Gunnlaugsson, T.; Glynn, M.; Tocci, G. M.; Kruger, P. E.; Pfeffer, F. M. Anion recognition and sensing in organic and aqueous media using luminescent and colorimetric sensors. Coord. Chem. Rev. 2006, 250, 3094-3117.

(c) 2008 by MDPI (http://www.mdpi.org). Reproduction is permitted for noncommercial purposes. 